\title{
What Is Relation of Urine Nitrites with Tooth Decay?
}

\author{
Muhammad Imran Qadir and Yasmeen Mureed* \\ Institute of Molecular Biology and Biotechnology, Bahauddin Zakariya University, Multan, Pakistan \\ *Corresponding Author: Yasmeen Mureed, Institute of Molecular Biology and Biotechnology, Bahauddin Zakariya University, Multan, \\ Pakistan.
}

Received: May 24, 2019; Published: July 03, 2019

DOI: $10.31080 /$ ASMI.2019.02.0290

\begin{abstract}
If there are nitrites are present in the body then they represent that bacterial infection is present in the urinary tract. There are different kinds of bacteria that have enzymes that convert the nitrates into nitrites. If nitrites are present in the urine then urine have the link with UTI. In these 100 students get involved from Bahauddin Zakariya University Multan, Pakistan. To determine the value of nitrites, students went into the lab with their urine samples and then they place a strip that is used to determine the concentration of nitrites. The strip is placed in the urine collection bag for few minute and then noted down the results. Project was based upon the data that was collected from the different students and then we designed project to know the relation among tooth decay and urine nitrites. Statistical analysis was performed to get the results. The obtained results showed that there was no relation among the urine nitrites.
\end{abstract}

Keywords: Urine Leukocytes; Tooth Decay; Cavity

\section{Introduction}

If there are nitrites are present in the body then they represent that bacterial infection is present in the urinary tract. There are different kinds of bacteria that have enzymes that convert the nitrates into nitrites. If nitrites are present in the urine then urine have the link with UTI. Infections of urinary tract are the most and dangerous problems due to the accumulation of the nitrites in the urine. The main reason of this disease are bacteria that effect the bladder, uterus and kidney. A doctor can easily diagnose the infection with the help of symptoms. But by drinking a large amount of water one can easily avoid from this disease. If nitrites are present in large concentration within the body then this can leads towards a condition which is known as nitrituria. A test that is performed to find out the concentration of nitrites in the urine is known as urinalysis.

Tooth decay is the common problem that is present in the children, females and also in the old people. In this, structure of the teeth is changed due to the attack of the bacteria and the protective sheath that is present upon the teeth and act like as a cover and protect teeth against the bacteria is also damaged due to use of sugary material, carbohydrates, proteins and starch that are present in large amount in the food. so this leads towards a hole formation occur within the teeth and it is a cavity. Tooth decay is a major health issue in many countries and as well as also in Pakistan. so to avoid this, use that food that contain the less amount of carbohydrates and proteins. Due to the too much use of these foods and sugary material like substances, the important chemicals are removed from the teeth and leads towards the distruction of the teeth.

\section{Material and Methods}

In these 100 students get involved from Bahauddin Zakariya University Multan, Pakistan.

Methods of measuring urine nitrites

To determine the value of nitrites, students went into the lab with their urine samples and then they place a strip that is used to determine the concentration of nitrites. The strip is placed in the urine collection bag for few minute and then noted down the results. 


\section{Project designing}

Project was based upon the data that was collected from the different students and then we designed project to know the relation among tooth decay and urine nitrites.

\section{Results}

The results showed in the tables (Table 1) showed that males had the less relation of urine nitrite with the tooth decay as compared to the females. Males had 44\% normal value when they had tooth decay and $2 \%$ when had no tooth decay. In case of positive when nitrites were present in their urine. In this case, values were $0 \%$ in both of the cases like had tooth decay or not (Table 2) showed, in female's case, that had normal value or no nitrites were present in their urine the values were $79 \%$ in case of had tooth decay and $60 \%$ when had no tooth decay. While when they had nitrites in their urine then they had $2 \%$ when they had tooth decay and also $2 \%$ when they had no tooth decay.

\begin{tabular}{|l|c|c|}
\hline Males & Negative & Positive \\
\hline Have tooth decay & $44 \%$ & $0 \%$ \\
\hline Have no tooth decay & $2 \%$ & $0 \%$ \\
\hline
\end{tabular}

Table 1: Impact of urine nitrites on tooth decay in males.

\begin{tabular}{|l|c|c|}
\hline Females & Negative & Positive \\
\hline Have tooth decay & $79 \%$ & $2 \%$ \\
\hline Have no tooth decay & $60 \%$ & $2 \%$ \\
\hline
\end{tabular}

Table 2: Impact of urine nitrites on tooth decay in females.

\section{Discussion}

If there are nitrites are present in the body then they represent that bacterial infection is present in the urinary tract. There are different kinds of bacteria that have enzymes that convert the nitrates into nitrites. If nitrites are present in the urine then urine have the link with UTI. Tooth decay is the common problem that is present in the children, females and also in the old people. In this, structure of the teeth is changed due to the attack of the bacteria and the protective sheath that is present upon the teeth and act like as a cover and protect teeth against the bacteria is also damaged due to use of sugary material, carbohydrates, proteins and starch that are present in large amount in the food. In this there was relation of tooth decay and urine nitrites.

\section{Conclusion}

The obtained results showed that there was no relation among the urine nitrites due to high percentage of negative and low percentage of positive [1-11].

\section{Bibliography}

1. Qadir MI and Malik SA. "Comparison of alterations in red blood cell count and alterations in hemoglobin concentration in patients suffering from rectal carcinoma undergoing 5-fluorouracil and folic acid therapy". Pharmacologyonline 3 (2010): 240-243.

2. Qadir MI and Noor A. "Anemias. Rare and Uncommon Diseases. Cambridge Scholars Publishing. Newcastle, England. (2018).

3. Qadir MI and Javid A. "Awareness about Crohn's Disease in biotechnology students". Global Advanced Research Journal of Medicine and Medical Sciences 7.3 (2018): 062-064.

4. Qadir MI and Saleem A. "Awareness about ischemic heart disease in university biotechnology students". Global Advanced Research Journal of Medicine and Medical Sciences 7.3 (2018): 059-061.

5. Qadir MI and Ishfaq S. "Awareness about hypertension in biology students". International Journal of Pharmaceutical Research 7.5 (2018): 095-097.

6. Qadir MI and Mehwish. "Awareness about psoriasis disease". International Journal Modified Pharma Research 7.2 (2018): 17-18.

7. Qadir MI and Shahzad R. "Awareness about obesity in postgraduate students of biotechnology". International Journal of Pharmaceutical Research 7.2 (2018): 14-16.

8. Qadir MI and Rizvi M. (2018) "Awareness about thalassemia in post graduate students". MOJ Lymphology and Phlebology 2.1 (2018): 14-16.

9. Qadir MI and Ghalia BA. "Awareness survey about colorectal cancer in students of M. Phil Biotechnology at Bahauddin Zakariya University, Multan, Pakistan". Nov Appro in Can Study, 1.3 (2018): NACS.000514.2018.

10. Qadir MI and Saba G. "Awareness about intestinal cancer in university student". Nov Appro in Can Study, 1.3 (2018): NACS.000515.2018.

11. Suadicani P., et al. "Airborne occupational exposure, ABO phenotype and risk of ischaemic heart disease in the Copenhagen Male Study". Journal of Cardiovascular Risk 9.4 (2002): 191198.

\section{Volume 2 Issue 8 August 2019} (C) All rights are reserved by Muhammad Imran Qadir and Yasmeen Mureed. 